\section{Une nouvelle} variété de substance amyloïde associée au diabète

Des dépôts amyloïdes sont trouvés très souvent dans les îlôts pancréatiques de Langerhan (qui sécrètent l'insuline) au cours du diabète de type 2 (non insulinodépendant). Des dépôts identiques sont observés dans les tumeurs sécrétant de l'insuline (ou insulinomes), dans les ilôts de chats ou de singes diabétiques et enfin, en moindre quantité, dans les ilôts pancréatiques de personnes âgées non diabétiques. Deux groupes de chercheurs [1, 2] viennent d'isoler et de caractériser cette substance amyloïde, différente de toutes celles jusqu'à présent étudiées. Cette substance est composée d'un polypeptique baptisé par les uns insulinoma associated polypeptide ou IAPP et par les autres diabetes associated peptide ou DAP. Ces deux peptides sont probablement identiques et ont une homologie importante avec le calcitonin gene-related peptide (CGRP). Des anticorps dirigés contre le CGRP ont été obtenus; ils ont permis de montrer que le DAP est également présent dans les cellules des ilôts de sujets non diabétiques. Dans le diabète de type 2, y a-t-il synthèse de $D A P$ ou d'IAPP normal en excès ou synthèse d'un peptide légèrement anormal qui se dépose dans le tissu et conduit à la formation des fibrilles amyloïdes? Comment le dépôt de ce peptide altère-t-il la fonction des ilôts? Le dépôt de substance amyloïde est-il une des causes du diabète de type 2 ?

\section{J.-P. G.}

\footnotetext{
1. Westermark P, Wernstedt C, O'Brien TD, Hayden DW, Johnson $\mathrm{KH}$. Islet amyloid in type 2 human diabetes mellitus and adult diabetic cats contains a novel putative polypeptide hormone. Am J Pathol 1987 ; 127 : 414. 2. Clark A, Cooper CJS, Lewis CE, et al. Islet amyloid formed from diabetes-associated peptide may be pathogenic in type-2 diabetes. Lancel, $1987 ; 2$ : 231-4
}

$\mathrm{m} / \mathrm{s} n^{\circ} 10$ vol. 3, décembre 87
L'érythropoïétine pourrait être très efficace dans le traitement de l'anémie du prématuré. Ces anémies sont vraisemblablement dues, en effet, à une sécrétion insuffisante d'érythropoïétine, correspondant au changement du site de synthèse (hépatique chez le foetus, rénal chez l'adulte). Il existe, chez ces enfants, une grande quantité de précurseurs circulants des érythroblastes répondant à l'érythropoiétine. L'existence d'érythropoíétine obtenue par génie génétique, maintenant disponible, permet donc d'entrevoir un traitement efficace de ces anémies qui sont parfois sévères.

[Shannon KM, et al. $N$ Engl J Med 1987 ; 317 ; 728-33.]

- L'hypercalcémie paranéoplasique est due à la sécrétion par le tissu tumoral d'une hormone jusqu'àlors inconnue, ayant de faibles homologies avec la parathormone. L'ADN complémentaire de cette hormone a été cloné à partir de cellules tumorales et la séquence protéique correspondante a été déduite de la séquence nucléotidique. La protéine hormonale mature a 141 acides aminés, le prépropeptide ayant 36 résidus $\mathrm{NH}_{2}$ terminaux supplémentaires. Il existe, au niveau de l'extrémité $\mathrm{NH}_{2}$ terminale du polypeptide mature, une zone d'homologie importante avec la parathormone : 11 résidus identiques sur 16. En revanche, le reste de la séquence diverge entre ces deux hormones. L'effet biologique du polypeptide tumoral semble identique à celui de la parathormone et il est possible que ces deux hormones se fixent au même récepteur. Des travaux ultérieurs diront si cette nouvelles hormone hypercalcémiante est normalement produite dans certai- nes cellules et à un stade particulier du développement.

[Suva LJ, et al. Science 1987 ; 237: 893-6]

Le TNF (tumor necrosis factor) jouerait un rôle central dans l'atteinte cérébrale au cours des accès palustres. Des complications cérébrales ne s'observent que dans une faible proportion (moins de $1 \%$ ) des cas de paludisme à Plasmodium falciparum, mais dans un pourcentage beaucoup plus élevé dans les formes mortelles. Certaines souches de souris, par exemple CBA/CA, présentent une sensibilité du système nerveux à une souche de Plasmodium berghei, alors que d'autres lui sont réfractaires. Grau et al. [1] ont trouvé que l'activité du $\mathrm{TNF} \alpha$ sérique (tumor necrosis factor) est élevée seulement chez les animaux sensibles ; cette élévation est empêchée par l'injection de sérum anti-TNF $\alpha$, qui protège également contre l'atteinte cérébrale. Le TNF, appelé aussi cachectine $\left(\mathrm{m} / \mathrm{s} n^{\circ} 1\right.$, vol. 2, p. 49 et $n^{\circ} 2$, vol. $\left.3, p .112\right)$ a un large spectre d'activités biologiques ; il est produit par les macrophages et paraît jouer un rôle important dans les phénomènes inflammatoires. C'est probablement l'accumulation et l'activation locales de macrophages qui est responsable des lésions du système nerveux central. Des essais préliminaires ont montré une élévation du TNF chez certains sujets impaludés.

Il faut toutefois rester prudent dans l'interprétation, car le TNF possède aussi des propriétés toxiques vis-à-vis de plusieurs souches de parasites du type Plasmodium; il pourrait donc exercer des actions soit bénéfiques, soit adverses, selon des modalités encore mal définies.

[1. Grau GE, et al. Science 1987 ; 237: 1210-2.]

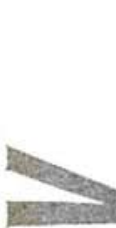

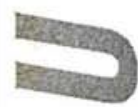

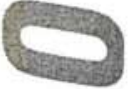

